\title{
Procurement in Short Supply Chains: Lessons Learned from the Tourism Industry
}

Argyropoulou Maria ${ }^{1 \uparrow}$, Argyropoulou Rachel ${ }^{1}$, Folinas Dimitris $^{2}$, Misopoulos Fotios ${ }^{1}$, Najacaj Suela ${ }^{2}$

${ }^{1}$ Management School, University of Liverpool, United Kingdom

${ }^{2}$ Department of Supply Chain Management, International Hellenic University, Greece

\begin{tabular}{l} 
ARTICLE INFO \\
\hline Article History \\
Received 11 November $2019 ;$ \\
Accepted 6 December 2019
\end{tabular}

JEL Classifications $\mathrm{Z} 32$

\section{ABSTRACT}

\section{Purpose:}

This paper explores the procurement management strategies adopted in 100 five-star hotels operating in a highly touristic area in South Greece. The study identifies and discusses the benefits and the challenges of managing short supply chains in the selected region.

Design/methodology/approach:

Quantitative data were gathered by using a questionnaire with 16 closed-ended and 3 open-ended questions. The sample included the Managing Directors and some Administrators. The questionnaire was filled in between April 2017 and June of the same year.

Findings:

The majority of the respondents prefer to do business with local suppliers for a variety of reasons, the most important being the boost of local economy and immediate delivery which improves response time. High prices of local products and the availability of sufficient quantities were found the main concerns for the smooth running of operations. Research limitations/implications:

The research uses data from two prefectures of Crete; a wider sample including other

Keywords:

Short Supply Chains,

Hospitality industry,

Sourcing, Greece prefectures in Greece and in South Europe would provide a more holistic view on the effectiveness of short food supply chains.

Originality/value:

This paper makes a contribution by examining how short supply chains can be developed in local economies. This paper explores the procurement management strategies adopted in 100 five-star hotels operating in a highly touristic area in South Greece. The study identifies and discusses the benefits and the challenges of managing short supply chains in the selected region. The majority of the respondents prefer to do business with local suppliers for a variety of reasons, the most important being the boost of local economy and immediate delivery which improves response time. High prices of local products and the availability of sufficient quantities were found the main concerns for the smooth running of operations. Supplier selection criteria are also discussed.

\section{Introduction}

The dynamic nature of the international and domestic business environment has made many businesses consider their suppliers as an extension of their company in order to ensure that the right amount and quality of materials and services is procured at the right time and best possible price. In recent years, shortening of supply chains, and especially in the food sector, has become a notable phenomenon, as these networks have been linked to quality 'turn' food (Aubry and Kebir, 2013) Short supply chains are characterized by strong relationships and synergies between buyers and local food suppliers (Frash, DiPietro and Smith, 2015). This phenomenon becomes even more remarkable in the hospitality industry due to the combination of two important drivers: faster delivery of products and services, and improved product quality (O’Donovan, Quinlan and Barry, 2012). 
Managing supply chains in the tourism industry is not easy for tourism-related businesses, especially for hotels who struggle to maintain a respected position due to tough completion and uncertainty of demand (Metaxas, Chatzoglou and Koulouriotis, 2019). High quality hotel services and customer satisfaction are positively related to strategic purchasing and supply chain management (Fantazy, Kumar and Kumar, 2010) and the choice of suitable suppliers who can deliver and promote their local goods. This need gave rise to the formation of short supply chains which are more effective for the constant replenishment of high quality goods and the seamless business operations (Onder and Kabadayi, 2015). Sourcing, therefore, is a valuable 'tool' for cost reduction, shortening of lead-times, and quality improvements (Oberoi and Khamba, 2005, p.279).

In light of the above analysis, this paper aims at the expansion of our knowledge on short supply chain networks and examines the procurement management strategies in the hotel industry focusing on the relationship with local suppliers. The companies selected for this research are the top five-star hotels of the prefectures of Heraklion and Lassithi in Crete (South Greece), which is an important tourist destination. At this point, it should be pointed out, that tourism is the most important sector in which the country has unquestionably comparative advantages due to its history and culture, natural environment and climate. The tourism sector represents an important part of the Greek economy, contributing significantly to the country's Gross National Product (GDP) occupying, either directly or indirectly, a large part of the workforce (Guduraš, 2014). The Greek tourism sector supports the establishment of local supply chain networks as local producers of famous products are located near the famous touristic destinations (Panagou, Nychas and Sofos, 2013,). The contribution of the paper lies in understanding how short supply chains can be developed in local economies by exploring strategies and relationships with local suppliers. The paper is structured as follows: The next section provides the literature review on the social, economic and environmental benefits of short supply chains. Section 3 discusses the methodology and quantitative results. The last section presents the main conclusions and highlights the limitations of this research along with suggestions for further research.

\section{Short supply chain benefits}

A simple definition of the short supply chain is a "supply chain involving a limited number of economic operators, committed to cooperation, local economic development, and close geographical and social relations between producers, processors and consumers" (Jarzębowski and Pietrzyck, 2018, p. 198). Local or short supply chains have economic, social and environmental benefits for all the members of the supply chain (De Fazio, 2016). These are briefly discussed in the subsequent paragraphs.

\subsection{Social benefits}

The synthesis of the pertinent literature (Bimbo et al, 2015; Tanasă, 2014; Hunt, 2007) revealed a list of advantages for any regional economy and companies involved in short supply chains: a) The development of social interaction and trust between producers and consumers, b) The improvement of the so-called social capital, c) The enhancement of the sense of community, and d) The increase of consumers' knowledge on and understanding of concepts related to food, agriculture and environment, which in some cases might result in change in behavior (for example to green products). The social benefits of Local Supply Chains are most likely to be associated with the development of a sense of community within a local society, the exchange of knowledge and know-how, and the development of skills at an individual and social level which, in turn, are related to health and well-being. In this context, short supply chains usually focus on promoting social change, through the training of people on the values of sustainability related to environmental as well as social justice campaigns.

\subsection{Economic benefits}

The economic impact of Local Chain Supply Chains is difficult to be determined with precision. It is often extremely difficult to obtain financial data for many of the programs and actions developed at the local level, given their size, nature and scope, since many stakeholders fail to systematically collect or systematically publish such data (Renting, Marsden and Banks, 2003).

Understanding the economic impact of Local Chain Supply Chains is, therefore, complex. It is common for rural businesses to use a combination of individual "small" supply chains (or even large supply chains) and it is, therefore, difficult to separate the financial contribution of each partner to the total turnover and profits. In some cases, the "conventional" part of an enterprise's activities may be used to support or finance a local supply chain, particularly in the early stages of development of the latter (Renting, Marsden and Banks, 2003). Within a local supply chain, it is difficult to quantify the effect on the employment of local workers due to the complex combination of full, partial and seasonal employment, as well as the mix of family work with volunteers and local trainee workers. In order to effectively study employment and its results within the Local Supply Chains, the corresponding analysis should distinguish the different types of chains.

The economic benefits of local supply chains are associated with local sourcing, tight and fast-paced procurement and investments in the region. Consistent with these arguments, the pertinent literature and practice provide support to the positive impact of short supply chains on the boost of local economy through the increase in local sales and 
demand for regional products (Levett, \& Chandler, 2012; Marsden, Banks \& Bristow, 2002) which can increase farmers' income (Kimberly, Von Massow \& Joppe, 2017). Previous research, however, attests to the unsatisfactory improvement of local economy (e.g. Lass, Lavoie \& Fetter, 2005). The relative importance of local sales or local supply chains is related to factors such as the company's size, its geographic location, e.g. proximity to urban markets or tourist destinations, etc. It should be noticed that occasionally, farmers and / or local producers involved in local chains do not necessarily seek to maximize profits. They rather join in the network for reasons such as financial security or more equitable trade relations (Mundler and Laugheria, 2016), aiming at an improvement in their social life and professional recognition of farmers (Mundler and Laugheria, 2016). Nonetheless, it is worth noting that although the financial contribution of Local Chain Supply Chains may be relatively small, their impact on societal and environmental levels is significantly positive.

\subsection{Environmental benefits}

The research on the environmental impact of local supply chains is usually divided into two major categories: energy use / carbon footprint and all the other environmental implications. Localizing a supply chain might bring out many benefits towards sustainability in the local community but researchers seem to be sharing various opinions (Schmitt et al, 2016). For some authors local supply chains can have a significant positive impact on the environment in terms of reduction in carbon emissions and enactment of energy efficiency (e.g. Pelletier et al. 2011; Canfora, 2016), on the reduced use of chemical inputs, and on the reduction of packaging and waste (Mundler and Laughrea, 2016). This is not fully supported, however, by other findings. For example, Schlich et al. (2006) believe that Local Supply Chains and the concentration of economic activities in one region only cannot contribute to substantial environmental benefits, mainly due to the small production volume. Nonetheless, local supply chains can contribute to the reduction or even elimination of pesticide and livestock use, reduction of soil and water pollution and soil quality degradation, to the maintenance of water reserves, and, finally, to the minimization of food processing (Enjolras and Aubert, 2018).

\subsection{Short supply chain and customers}

Consumers purchasing or consuming products from Local Supply Chains seem to be generally satisfied with the support provided by the local producers, and there are credible indications that these consumers consider that local products have higher quality standards. As far as consumers' interest in Local Chain of Supply is concerned, there are indications that many consumers are willing to support similar chains for ethical and environmental reasons (Mundler and Laughrea, 2016). For the authors, consumers are generally happy with the promotion of local products as the circulation of money remains local and boosts the local economy (Mundler and Laughrea, 2016).

\section{Methodology and key findings}

For the purposes of this study, a questionnaire with 16 closed-ended and 3 open-ended questions was used. The questionnaire was filled in between April 2017 and June of the same year. Respondents were Managing Directors and Administrators of 100 five-star hotels of the prefectures of Heraklion and Lasithi in Crete. Table 1 summarizes the main variables used in this research along with the pertinent literature:

Table 1: Research variables

\begin{tabular}{|ll|}
\hline Questionnaire items & Literature \\
\hline Relative importance of goods and services all items & Salihoglu \& Gezici (2018) \\
Reasons for choosing local suppliers & \\
Quality & Inwood,Sharp Moore\&Stinner (2009) \\
Shorter lead time & Sharma , Gregoire \& Strohbehn (2009) \\
Cost & Sharma , Gregoire \& Strohbehn (2009) \\
Support of local community & Strohbehn \& Gregoire (2003) \\
Challenges from using local suppliers & \\
Inadequate distribution & Inwood, Sharp,Moore \& Stinner (2009). \\
Consistent supply & Curtis \& Cowee(2009) \\
Unavailability of resources & Kang \& Rajagopal (2014) \\
Seasonal availability & Kang \& Rajagopal (2014) \\
Inadequate quantity & Kang \& Rajagopal (2014) \\
\hline
\end{tabular}

The following paragraphs summarize the key findings. 


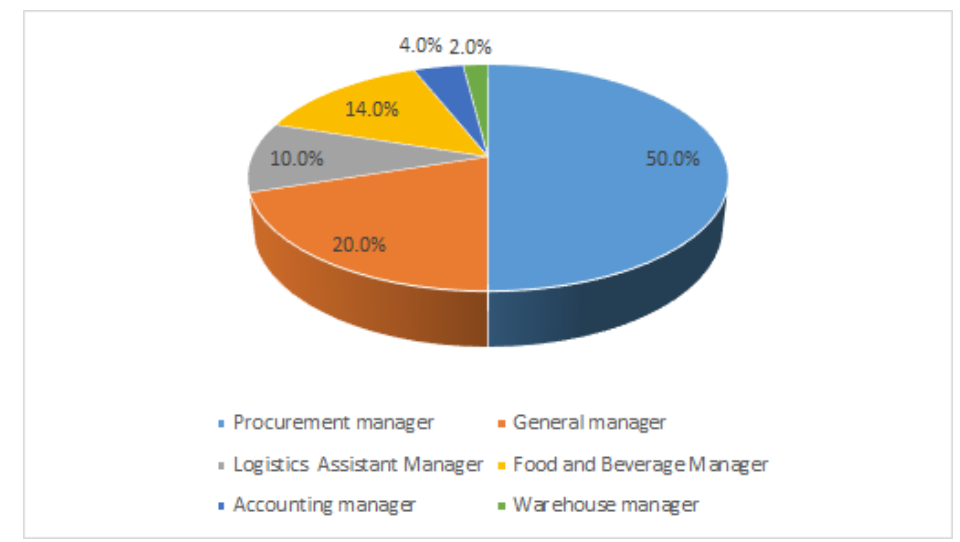

Figure 1: Profile of respondents

A closer look at Figure 1, reveals that all participants have experience in the sourcing and procurement process and can been considered as key informants for the collection of reliable data. More specifically, the respondents have considerable professional experience $(40 \%$ have 6 to 10 years' managerial experience in the accommodation sector, $38 \%$ from 1 to 5 years, whilst $22 \%$ have more than 10 years of experience).

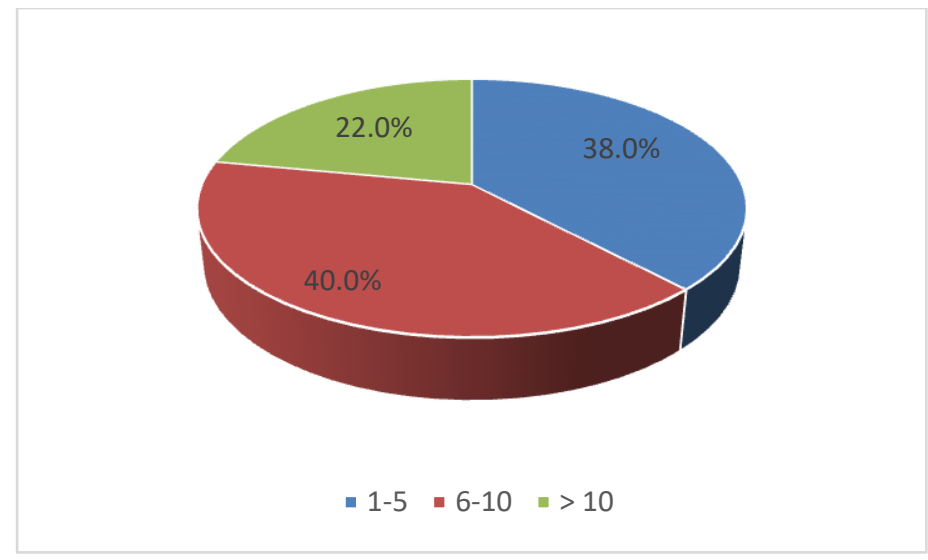

Figure 2: Work experience

The procurement department is in most cases responsible for the sourcing of goods and services (see Fig 3).

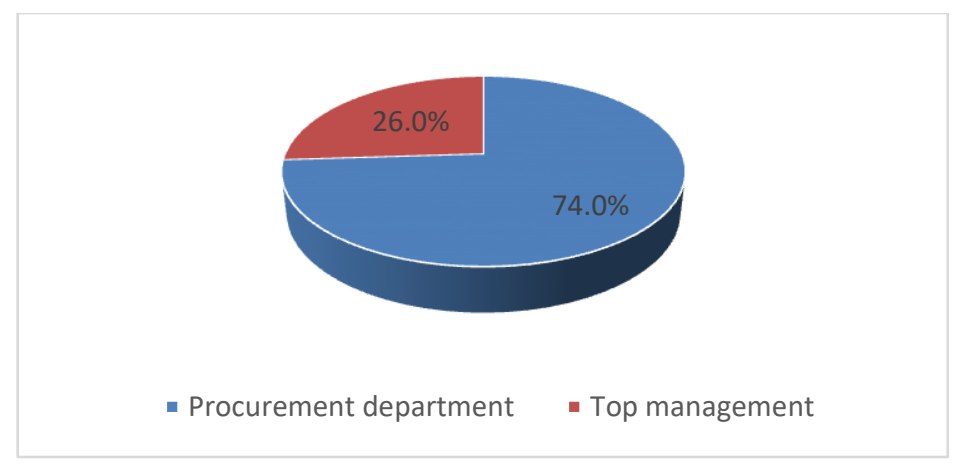

Figure 3: Sourcing responsibility

Respondents were asked to provide a list of the most critical supplies for the running of their operations. The analysis of the answers indicated that cleaning, food and beverages are the most important goods and services in this study (see table 2). The majority of hotel managers use local suppliers (see Fig. 4). 
Table 2: Relative importance of goods and services

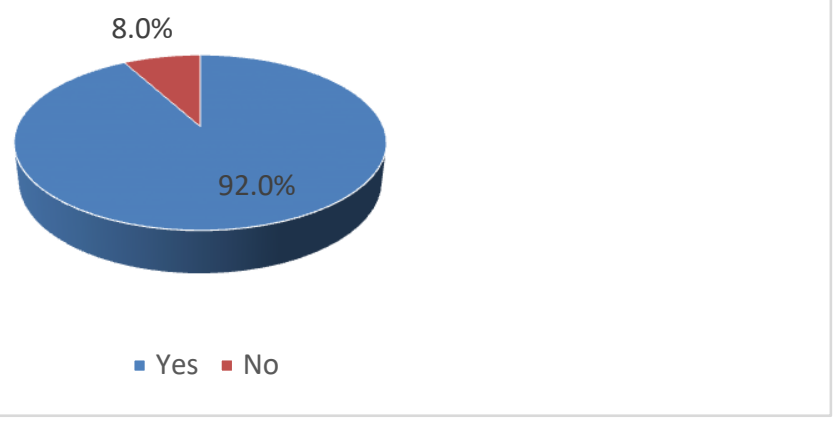

Figure 4: Use of local suppliers

Table 2: Relative importance of goods and services

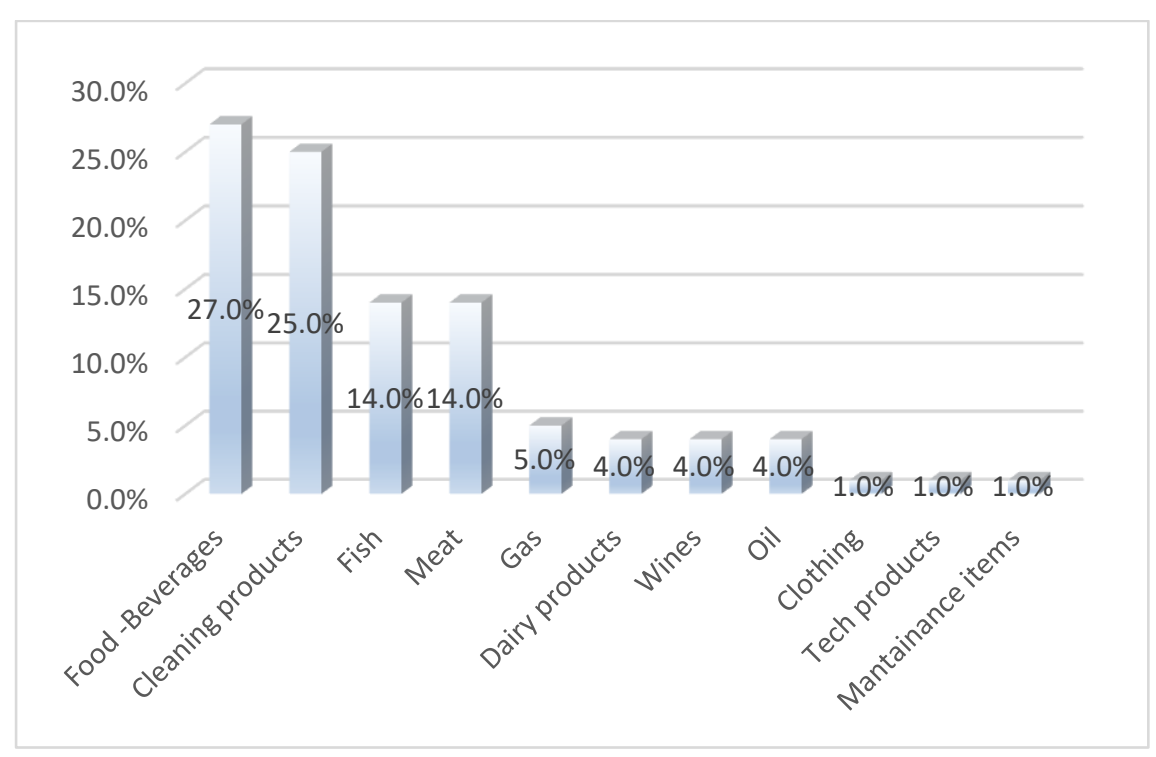

The reasons for choosing local suppliers are summarized in figure 5. It is worth noting that shorter lead times and support of local economy are deemed the most significant in the minds of the hotel managers (Fig 5).

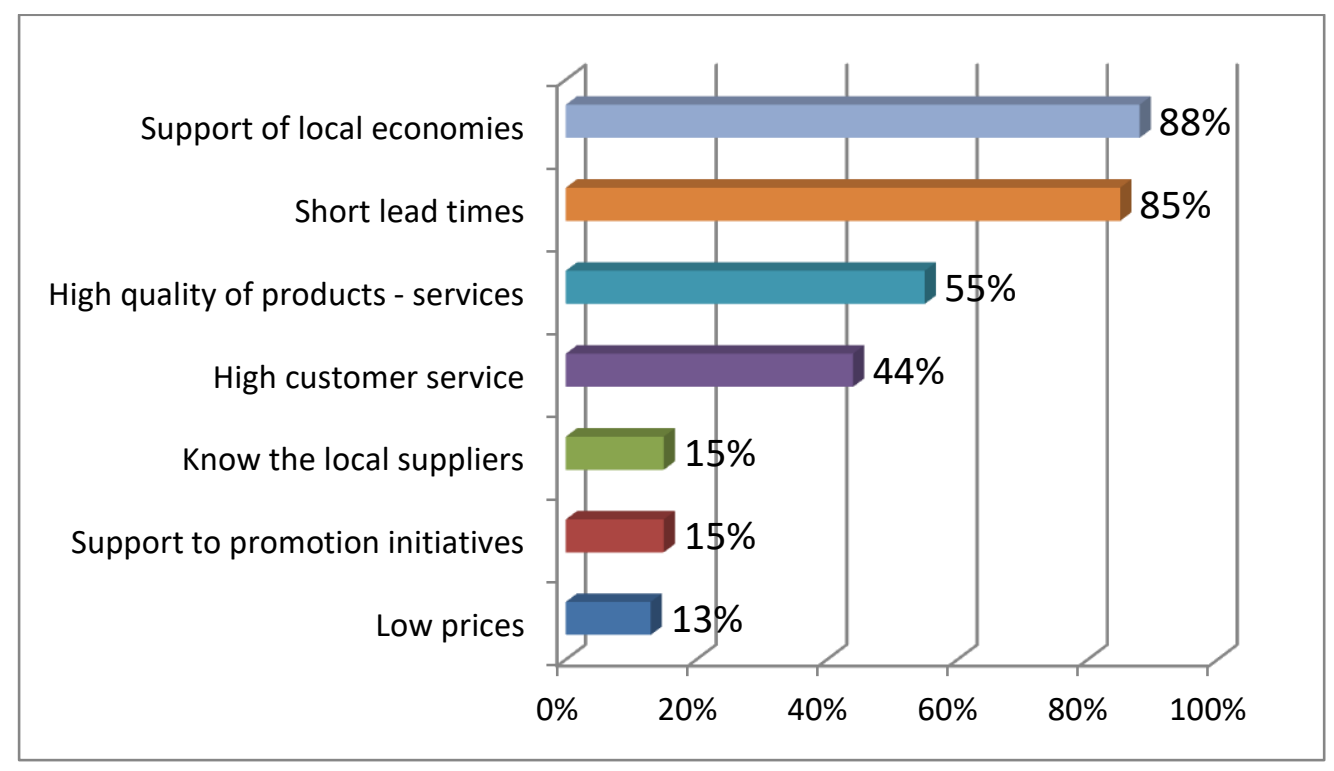

Figure 5. Reasons that hotel managers select local suppliers 
With regard to suggestions for better services, the hotel managers indicated lower prices, larger quantities with flexible payment methods (Fig. 6).

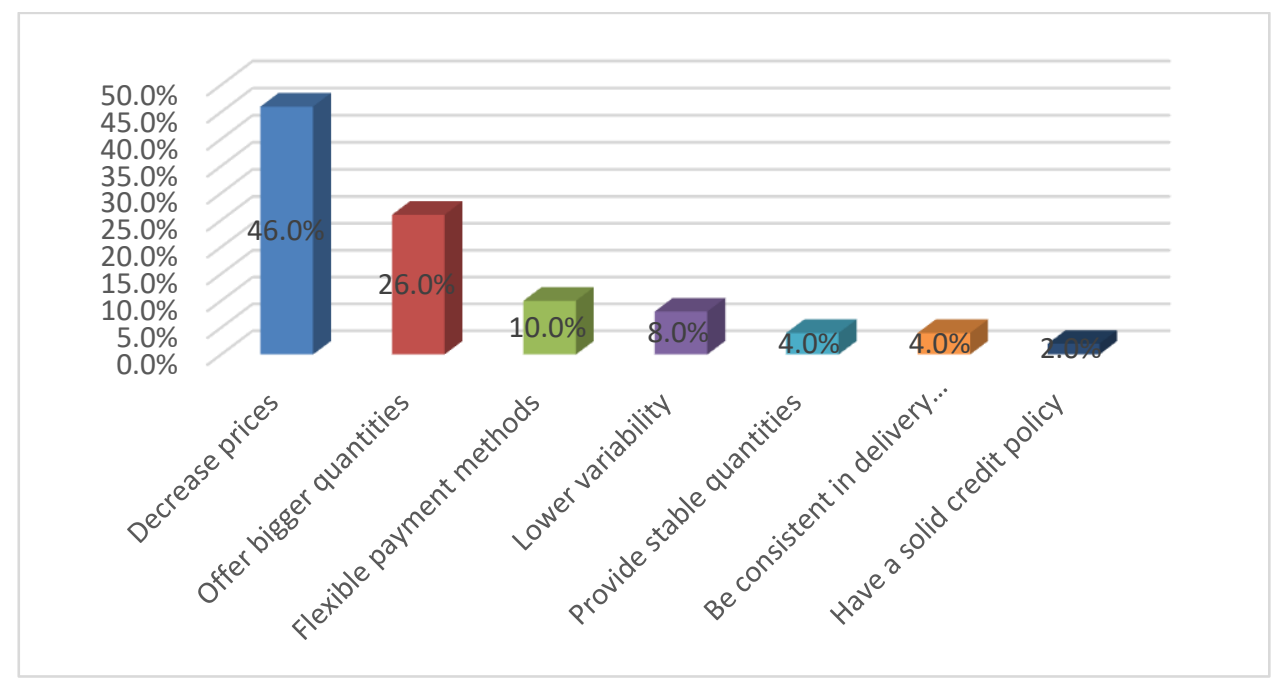

Figure 6: Suggestions made by hotel managers

When asked about the supplier selection criteria, surprisingly quality did not seem to matter. Most respondents agreed on the value for money (Fig. 7). The supplier evaluation methods are summarized in Figure 8.

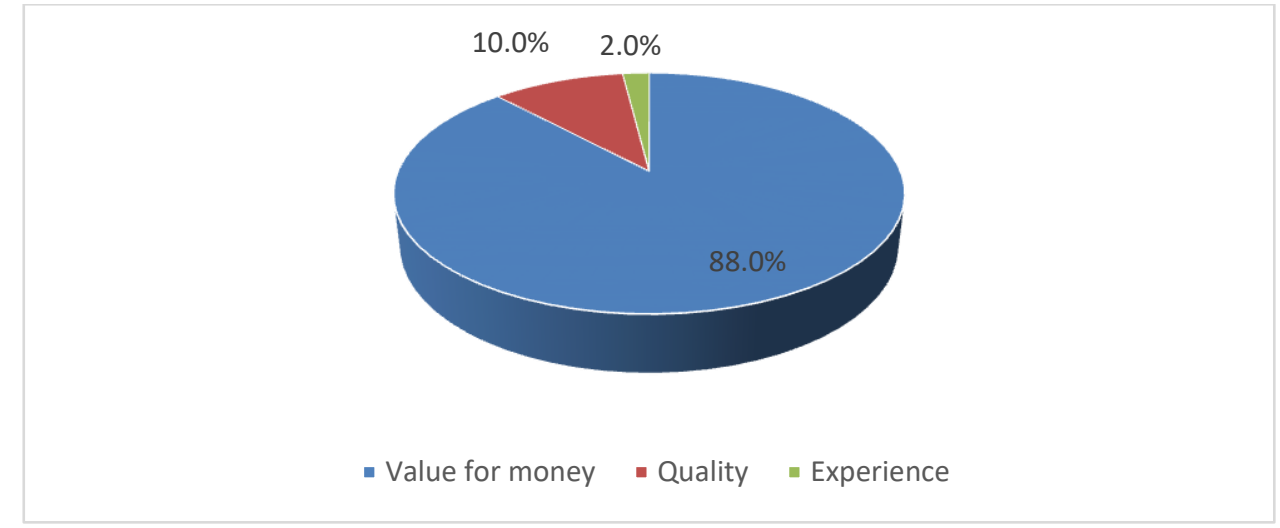

Figure 7: Supplier selection criteria

Finally, most hotels are certified and follow the ISO $22000(44 \%)$ and ISO 9001-2008 (34\%). $22 \%$ of respondents said that they maintain and use the HACCP standard. Specifically, most hotels in our sample have been certified with the ISO 22000 quality management system; an internationally applicable standard that defines the requirements for the development and implementation of an effective Food Safety Management System (see Fig.9). 


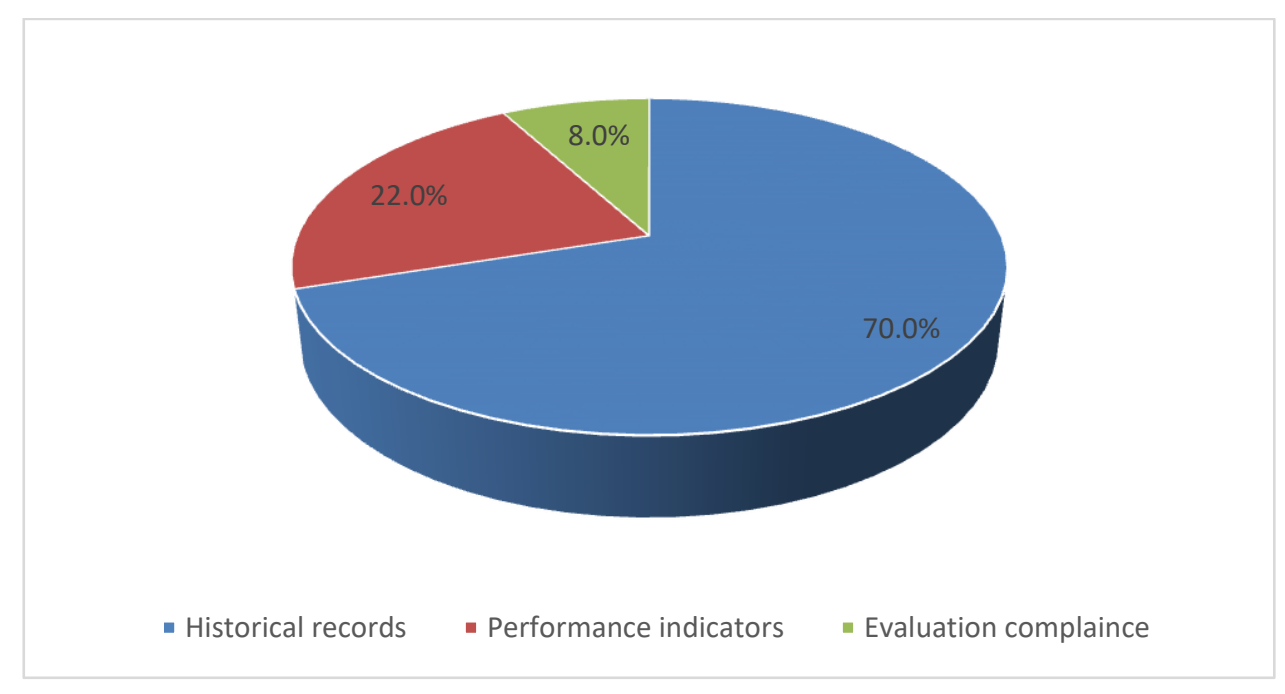

Figure 8: Supplier evaluation methods

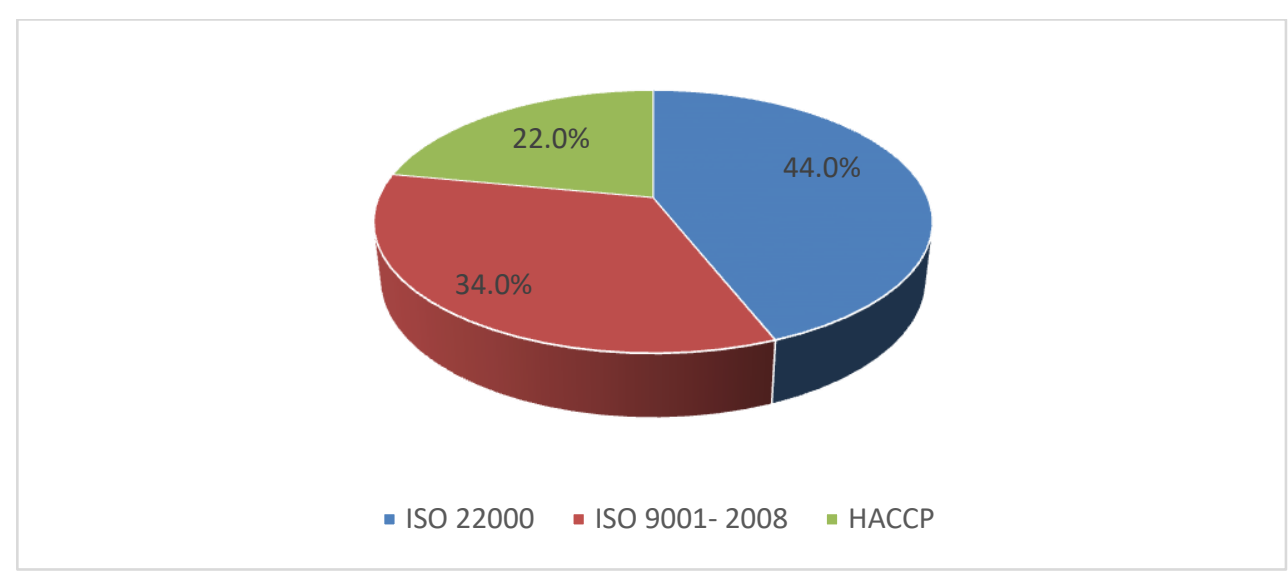

Figure 9: Certification by Quality Standards

\section{Conclusions}

The sample of this research includes one hundred five-star hotels located in the two prefectures of Crete (Lasithi and Heraklion). There is an upsurge in the short supply chains as supported by the findings of this research. In Greece and more specifically in Crete, the hospitality industry seems to acknowledge the benefits that can be reaped from local sourcing. Hotel managers prefer to use local suppliers mainly as they wish to support the local economy and receive the goods and services in a timely fashion.

The supplier base of the hotels in Crete is sufficient to provide typical and traditional products that give a competitive edge. The survey showed that the five stars hotels in Crete follow the supply chain management trends. A key finding is that high prices and the need for flexible payment agreements are the main challenges when procuring locally. The hotel managers in this area consider that there is room for improvement in the quantities they could purchase. Consistent quality and year round available that have been found as key concerns in this field of research (Kang and Rajagopal, 2014), do not contribute substantially to the success of this study's supply chain. This may be attributed to the fact that Crete has a large pasture area as well as a large irrigated area, producing olives, vegetables, cereals and fruits (Udias et al, 2018).

This study is not without limitations. The implications of this research are based on two prefectures of Crete which is a rural area with rich agricultural activity. The findings, therefore, are likely to reflect local cultural preferences and perceptions that may not apply to other Greek or European regions. Another limitation relates to whether the representative sample is sufficient to infer generalized conclusions. Future studies can focus on different regions to capture different perceptions and provide new opportunities and best practices extending thus our understanding on this rather new but most interesting area of research. 
Future researchers can use the same approach to include other prefectures in Greece and in South Europe to examine the effectiveness of short food supply chains. The current EU policy puts great emphasis on these supply chains, funding several research programs regarding localization of the production, and setting legal frameworks and incentives to support such types of chains (Kneafsey et al, 2013). It is, therefore, necessary for future research to investigate the increasing phenomenon and provide recommendations that can develop local economies.

\section{References}

Aubry, C. and Kebir, L., 2013,"Shortening food supply chains: A means for maintaining agriculture close to urban areas? The case of the French metropolitan area of Paris", Food Policy, 41, pp. 85-93

Bimbo, F., Bonanno, A.,Nardone, G. andViscecchia, R., 2015, "The Hidden Benefits of Short Food Supply Chains: Farmers' Markets Density and Body Mass Index in Italy”, International Food and Agribusiness Management Review, 18,1 , pp. 1-16.

Canfora, I., 2016, "Is the short food supply chain an efficient solution for sustainability in food market?", Agriculture and Agricultural Science Procedia, 8, pp. 402-407.

Curtis, K., and Cowee, M, 2009, "Direct marketing local food to chefs: Chef preferences and perceived obstacles", Journal of Food Distribution Research, 40,2, pp.26-36.

De Fazio, M.,2016, “Agriculture and sustainability of the welfare: the role of the short supply chain”, Agriculture and Agricultural Science Procedia, 8, pp. 461-466.

Enjolras, G. and Aubert, M., 2018, "Short food supply chains and the issue of sustainability: acase study of French fruit producers", International Journal of Retail \& Distribution Management, 46,2, pp.194-209

Fantazy, K.A., Kumar, V. and Kumar, U., 2010, "Supply management practices and performance in the Canadian hospitality industry”, International Journal of Hospitality Management, 29, pp. 685-693

Frash Jr, R.E, DiPietro, R. and Smith, W., 2015, "Pay More for McLocal? Examining Motivators for Willingness to Pay for Local Food in a Chain Restaurant Settin”, Journal of Hospitality Marketing \& Management, 24,4, pp. 41 1-434.

Guduraš, D., 2014, "Economic Crisis and Tourism: Case of the Greek Tourism Sector" Economic Thought and Practice, 2, pp. 613-632 available at https://hrcak.srce.hr/130855

Hunt, A.R., 2007, "Consumer interactions and influences on farmers' market vendors", Renewable Agriculture and Food Systems, 22,1, pp. 54-66.

Inwood,S., Sharp,J., Moore, R. and Stinner, D., 2009 "Restaurants, chefs and local foods: insights drawn from application of a diffusion of innovation framework", Agriculture and human value, 26,3, pp 177-191.

Jarzębowski, S. and Pietrzyck, K., 2018, "The Concept of Short Supply Chains in the Food Economy. The Common Agricultural Policy of the European Union - the present and the future, EU Member States point of view", Wigier, M., Kowalski, A. series "Monographs of Multi-Annual Programme" no 73.1, IAFE-NRI, Warsaw 2018, ISBN: 978-837658-743-1. Available at SSRN: https://ssrn.com/abstract=3202653

Kang, S. and Rajagopal, L., 2014, "Perceptions of Benefits and Challenges of Purchasing Local Foods Among Hotel Industry Decision Makers”, Journal of Foodservice Business Research, 17, pp. 301-322.

Kimberly, T. F., Von Massow, M. and Joppe, M., 2017, "Strengthening Farmers-Hotel Supply Chain Relationships: A Service Management Approach”, Tourism Planning \& Development, 14,2, pp. 198-219.

Kneafsey, M., L. Venn, U. Schmutz, B. Balázs, L. Trenchard, T. Eyden-Wood, E. Bos, G. Sutton, and Blackett, M., 2013, "Short food supply chains and local food systems in the EU. A state of play of their socio-economic characteristics" European Commission Report.

Lass, D.A., Lavoie, N. \& Fetter, T.R., 2005, "Market Power in Direct Marketing of Fresh Produce: Community Supported Agriculture Farms”, Working paper No. 2005-2, Dept. of Res. Econ., University of Massachusetts, Amherst. Levett, M. \& Chandler, A.E., 2012, "Maximising Development of Local Content Across Industry Sectors in Emerging Markets", Washington DC: Centre for Strategic \& International Studies.

Marsden, T., Banks, J. and Bristow, G., 2002, "The social management of rural nature: understandingagrarian-based rural development”, Environment and Planning A, 34, p.p. 809-825.

Metaxas, I.N.,. Chatzoglou, P.D. and Koulouriotis, D.E., 2019, "Proposing a new modus operandi for sustainable business excellence: the case of Greek hospitality industry”, Total Quality Management \& Business Excellence, 30,56, pp. 499-524.

Mundler, P. and Laughrea, S., 2016, "The contributions of short food supply chains to territorial development: A study of three Quebec territories”, Journal of Rural Studies, 45, pp. $218-229$.

Oberoi, J.S. and Khamba, J.S., 2005, "Strategically managed buyer-supplier relationships across supply chain: an exploratory study," Human Systems Management, 24, 4, pp. 275-283.

O’Donovan, I., Quinlan, T. and Barry, T., 2012, "From farm to fork Direct supply chain relationships in the hospitality industry in the south east of Ireland”, British Food Journal, 114,4, pp. 500-515.

Onder, E. and kabadayi, N., 2015, "Supplier Selection in Hospitality Industry Using ANP", International Journal of Academic Research in Business and Social Sciences, 5, 1, pp. 166-186

Panagou, E.Z., Nychas, G.J.E. and Sofos, J.N., 2013, "Types of traditional Greek foods and their safety", Food Control, 29, pp. 32-41. 
Pelletier, N., Audsley, E., Brodt, S., Garnett,T., Henriksson, P., Kendall, A., Klaas Jan Kramer, K., Murphy, D., Nemecek, T. and Troell, M., 2011, "Energy Intensity of Agriculture and Food Systems", The Annual Review of Environment and Resources, 36, pp. 223-46.

Renting, H., Marsden, T.K. and Banks, J., 2003, "Understanding alternative food networks: exploring the roleof short food supply chains in rural development”, Environment and Planning A, 35, p.p. 393-411.

Salihoglu, G. and Gezici, F., 2018, "Geography of suppliers in the hospitality sector: The case of Alanya”, Tourism Management 65, pp. 41-54.

Schlich, E., Biegler, I., Hardtert, B., Luz, M., Schroder, S., Scroeber, J., and Winnebeck, S., 2006, "La consommation alimentaire d'énergie finale de différents produits alimentaires: un essai de comparaison”, Courrier de l'environnement de l'INRA, 53, pp. 111-120.

Schmitt, E., Keech, D., Maye, D., Barjolle, D. and Kirwan, D., 2016, "Comparing the Sustainability of Local and Global Food Chains: A Case Study of Cheese Products in Switzerland and the UK”, Sustainability, 8,5, pp. 419-439.

Sharma, A., Gregoire, M. and Strohbehn, C., 2009, "Assessing Costs of Using Local Foods in Independent Restaurants”, Journal of Foodservice Business Research, 12,1, p.p 55-71.

Strohbehn, C.H. and Gregoire, M. B., 2003, "Institutional and commercial food service buyers' perceptions of benefits and obstacles to purchase locally grown and processed foods”, Leopold Center Completed Grant Reports. 205.

Available at https://lib.dr.iastate.edu/leopold_grantreports/205

Tanasă, L., 2014, "Benefits of Short Food Supply Chains for the Development of Rural Tourism in Romania as Emergent Country During Crisis”, Agricultural Economics And Rural Development, Year XI, no. 2/2014, București, pp.181-193.

Udias, A.,Pastori,M., Malagò, A., Vigiak, O., Nikolaidis, N.P. and Bouraoui, F.,2018, "Identifying efficient agricultural irrigation strategies in Crete", Science of The Total Environment, 633, pp. 271-284.

This is an Open Access article distributed under the terms of the Creative Commons Attribution Licence

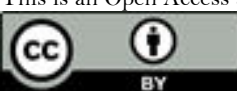

